\title{
FAKTOR-FAKTOR YANG BERHUBUNGAN DENGAN PELAKSANAAN TERAPI AKTIVITAS KELOMPOK DI RUANGAN PERAWATAN JIWA RUMAH SAKIT DAERAH MADANI PROVINSI SULAWESI TENGAH
}

\author{
Sugeng Adiono \\ Politeknik Kesehatan Kementerian Kesehatan Palu
}

\begin{abstract}
ABSTRAK
Upaya-upaya untuk meningkatkan mutu pelayanan keperawatan jiwa telah dilakukan oleh tenaga keperawatan, dengan melakukan kegiatan Terapi Aktivitas Kelompok (TAK). Masalah-masalah keperawatan jiwa yang dapat diatasi melalui TAK adalah klien dengan isolasi sosial, halusinasi, menarik diri dan harga diri rendah. Namun demikian TAK belum dijalankan oleh perawat secara teratur. Hal ini karena kemampuan perawat dalam menjalankan kegiatan TAK belum memadai. Penelitian ini bertujuan untuk mengetahui faktor-faktor yang berhubungan dengan pelaksanaan Terapi Aktivitas Kelompok (TAK) di ruangan perawatan jiwa RSD Madani Propinsi Sulawesi Tengah.

Jenis penelitian adalah Cross Sectional Study. Dengan variabel dependen pelaksanaan TAK dan variabel independen pengetahuan, pengalaman dan sikap perawat. Populasi dalam penelitian ini adalah perawat di ruangan Manggis, Sarikaya dan Salak sejumlah 33 perawat. Teknik sampling yang digunakan adalah total population. Data primer diolah dengan menggunakan analisis univariat dan analisis bivariat menggunakan uji Chi-Square, jika syarat uji tidak terpenuhi maka digunakan penggabungan sel dan uji alternatif yakni uji Fisher exact.

Hasil penelitian terhadap 33 responden menunjukan bahwa; Lebih banyak yang melaksanakan TAK dengan kategori kurang baik sejumlah 21 orang (63,6\%); Lebih banyak yang pengetahuannya dalam kategori kurang baik tentang TAK sejumlah 21 orang $(63,6 \%)$; Lebih banyak yang tidak pernah mengikuti pelatihan TAK sejumlah 27 orang $(81,8 \%)$; Lebih banyak yang sikapnya dalam kategori kurang baik terhadap TAK sejumlah 19 orang $(57,6 \%)$. Hasil analisis bivariat menunjukan; ada hubungan faktor pengetahuan perawat $(p=0,000)$, pengalaman perawat $(p=0,016)$ dan sikap perawat $(p=0,000)$ dengan pelaksanaan TAK di ruangan perawatan jiwa RSD Madani Propinsi Sulawesi Tengah.

Disimpulkan bahwa ada hubungan pengetahuan, pengalaman dan sikap perawat dengan pelaksanaan Terapi Aktivitas Kelompok (TAK) di ruangan perawatan jiwa RSD Madani Propinsi Sulawesi Tengah. Saran kepada rumah sakit agar melakukan pelatihan dan seminar tentang TAK.
\end{abstract}

Daftar Pustaka : 24 (2005-2015)

Kata Kunci : Terapi aktivitas kelompok, pengetahuan, pengalaman, sikap

\section{PENDAHULUAN}

World Health Organization (WHO) memberi pengertian bahwa kesehatan jiwa bukan hanya tidak ada gangguan jiwa, melainkan mengandung berbagai karakteristik yang positif yang menggambarkan keselarasan dan keseimbangan kejiwaan yang mencerminkan kedewasaan kepribadiannya. Sedangkan menurut UU Kesehatan Jiwa No. 3 Tahun 1996, sehat jiwa adalah kondisi yang memungkinkan perkembangan fisik, intelektual, emosional secara optimal dari seseorang dan perkembangan ini berjalan selaras dengan orang lain (Yosep, 2009).

Upaya-upaya untuk meningkatkan mutu pelayanan keperawatan jiwa telah 
dilakukan oleh tenaga keperawatan, dengan melakukan kegiatan Terapi Aktivitas Kelompok (TAK) sebagai terapi atau tindakan keperawatan jiwa. Terapi aktivitas kelompok merupakan bentuk terapi modalitas yang didasarkan pada pembelajaran hubungan interpersonal. Dengan bergabung dalam kelompok, klien dapat saling bertukar pikiran dan pengalaman dan mengembangkan pola perilaku baru (Achiryani dkk, 2005).

Setiap kelompok mempunyai struktur dan identitas tersendiri. Kekuatan kelompok memberikan konstribusi pada anggota dan pimpinan kelompok untuk saling bertukar pengalaman dan memberi penjelasan untuk mengatasi masalah anggota kelompok. Dengan demikian kelompok dapat dijadikan sebagai wadah untuk praktek dan arena uji coba kemampuan berhubungan dan berperilaku dengan orang lain (Purwaningsih dan Karlina, 2009).

Masalah-masalah keperawatan jiwa yang dapat diatasi melalui Terapi Aktivitas Kelompok (TAK) adalah klien dengan isolasi sosial, halusinasi, menarik diri dan harga diri rendah. Untuk pasien dengan masalah menarik diri dapat pula diberikan Terapi Aktivitas Kelompok Sosialisasi (TAKS) untuk mensosialisasikan pasien dalam lingkungan kelompok (Keliat, 2007).

Melalui Terapi Aktivitas Kelompok (TAK) masing-masing pasien saling membantu dalam membangun hubungan, serta mengubah perilaku destruktif dan maladaptif. Kekuatan terapi aktivitas kelompok ini terletak pada kontribusi dari setiap anggota dan pemimpin dalam mencapai tujuan bersama (Keliat, 2007).

Namun demikian Terapi Aktivitas Kelompok (TAK) belum dijalankan oleh perawat secara teratur. Hal ini karena kemampuan perawat dalam menjalankan kegiatan TAK belum memadai, pedoman pelaksanaan dan perawatan yang mewajibkan pelaksanaan TAK di Rumah Sakit belum ada. Selain itu referensi yang menjelaskan model TAK, faktor-faktor yang mempengaruhi dan dampak TAK terhadap klien dengan gangguan jiwa belum diketahui secara jelas di Indonesia (Keliat, 2007).

Data dari RSD Madani Propinsi Sulawesi Tengah, menunjukan jumlah penderita skizofrenia pada tahun 2012 adalah 579 orang, pada tahun 2013 sebanyak 693 orang, sedangkan pada tahun 2014 sebanyak 443 orang. Adapun data terakhir bulan Januari-Mei 2015, kasus skizofrenia sejumlah 268 orang (RSD Madani Sulawesi Tengah, 2015).

Berdasarkan studi pendahuluan pada hari Senin tanggal 25 Juni 2015 yang didapat dari ruang rawat inap perawatan jiwa Rumah Sakit Daerah Madani, yang terdokumentasi untuk pelaksanaan TAK adalah sebagai berikut; Ruangan Manggis tidak pernah melakukan TAK; Ruangan Salak 4 kali tiap bulan pada tahun 2013 dan 2 kali pada tahun 2014; Ruangan Sarikaya 1 kali tiap bulan pada tahun 2013 dan 2014.

Berdasarkan uraian di atas peneliti tertarik melakukan penelitian tentang faktor-faktor yang berhubungan dengan pelaksanaan Terapi Aktivitas Kelompok (TAK) di ruangan perawatan jiwa RSD Madani Propinsi Sulawesi Tengah.

\section{METODE PENELITIAN (Methods)}

Jenis penelitian adalah analitik dengan menggunakan pendekatan Cross Sectional. Populasi dalam penelitian ini adalah perawat di ruangan Manggis, Sarikaya dan Salak RSD Madani Propinsi Sulawesi Tengah sejumlah 33 orang perawat. Sampel berjumlah 33 orang perawat (total populasi). Analisis data dilakukan uji statistik dengan menggunakan metode Chi Square $\left(\mathrm{X}^{2}\right)$ dengan kemaknaan a 0,05.

\section{HASIL (result)}

Hasil penelitian dalam bentuk data primer diperoleh melalui wawancara langsung pada responden mengenai pengetahuan perawat, pengalaman perawat mengikuti pelatihan, sikap perawat dan pelaksanaan Terapi Aktivitas 
Kelompok (TAK) di Ruangan Perawatan Jiwa RSD Madani Propinsi Sulawesi Tengah, pada bulan November 2015.

\section{Analisis Uivariat}

Pada penelitian ini, hasil analisis univariat akan menggambarkan variabel

\section{Tabel 1}

Distribusi Menurut pengetahuan perawat, pengalaman perawat mengikuti pelatihan, sikap perawat dan pelaksanaan Terapi Aktivitas Kelompok (TAK) di Ruangan

Perawatan Jiwa RSD Madani Propinsi Sulawesi Tengah

\begin{tabular}{|c|c|c|c|c|}
\hline No & Variabel & Kategori & $n=33$ & $\%$ \\
\hline & & Baik & 12 & 36,4 \\
\hline 1 & Pengetahuan Perawat & Kurang baik & 21 & 63,6 \\
\hline \multirow[t]{2}{*}{2} & Pengalaman Perawat & Pernah & 6 & 18,2 \\
\hline & mengikuti pelatihan & Tidak pernah & 27 & 81,8 \\
\hline \multirow{3}{*}{2} & & Baik & 14 & 42,4 \\
\hline & Sikap & Kurang baik & 19 & 57,6 \\
\hline & Pelaksanaan TAK & $\begin{array}{l}\text { Baik } \\
\text { Kurang baik }\end{array}$ & $\begin{array}{l}12 \\
21\end{array}$ & $\begin{array}{l}36,4 \\
63,6\end{array}$ \\
\hline
\end{tabular}

Sumber : Data primer yang diolah

Tabel 1 menunjukkan bahwa dari 33 responden lebih banyak yang pengetahuannya dalam kategori kurang baik tentang TAK sejumlah 21 orang $(63,6 \%)$, dari pada yang pengetahuannya dalam kategori baik sejumlah 12 orang $(36,4 \%)$.

Responden, yang tidak pernah mengikuti pelatihan TAK lebih banyak sejumlah 27 orang $(81,8 \%)$, dari pada yang pernah mengikuti pelatihan TAK sejumlah 6 orang $(18,2 \%)$.

Responden yang memiliki sikap kurang baik terhadap TAK lebih banyak

sejumlah 19 orang $(57,6 \%)$, dari pada yang memiliki sikap baik sejumlah 14 orang $(42,4 \%)$.

dari 33 responden lebih banyak yang melakukan pelaksanaan TAK dengan kategori kurang baik sejumlah 21 orang (63,6\%), dari pada yang melakukan pelaksanaan TAK dengan kategori baik sejumlah 12 orang $(36,4 \%)$.

\section{Analisis Bivariat}

a. Hubungan pengetahuan perawat dengan pelaksanaan TAK

Tabel 2

Hubungan Antara Pengetahuan Perawat Dengan Pelaksanaan Terapi Aktivitas Kelompok (TAK) di Ruangan Perawatan Jiwa RSD Madani

Propinsi Sulawesi Tengah

\begin{tabular}{|c|c|c|c|c|c|c|c|c|}
\hline \multirow{3}{*}{$\begin{array}{c}\text { Pengetahuan } \\
\text { Perawat }\end{array}$} & \multicolumn{4}{|c|}{ Pelaksanaan TAK } & \multirow{2}{*}{\multicolumn{2}{|c|}{ Total }} & \multirow{3}{*}{$\begin{array}{l}\text { p Value; Uji } \\
\text { Chi-square }\end{array}$} & \multirow{3}{*}{$\begin{array}{c}\text { Odds Ratio } \\
\text { (CI 95\%) }\end{array}$} \\
\hline & \multicolumn{2}{|c|}{ Baik } & \multicolumn{2}{|c|}{$\begin{array}{c}\text { Kurang } \\
\text { Baik }\end{array}$} & & & & \\
\hline & $\mathbf{f}$ & $\%$ & $\mathbf{f}$ & $\%$ & $\mathbf{n}$ & $\%$ & & \\
\hline Baik & 10 & 83,3 & 2 & 16,7 & 12 & 100 & \multirow{3}{*}{0,000} & \multirow{3}{*}{47,5} \\
\hline Kurang Baik & 2 & 9,5 & 19 & 90,5 & 21 & 100 & & \\
\hline Total & 12 & 36,4 & 21 & 63,6 & 33 & 100 & & \\
\hline
\end{tabular}

Sumber: Data primer 2015 
Tabel 2 menunjukkan bahwa dari 33 responden, 12 responden berpengetahuan baik dan pelaksanaan TAK baik sebanyak 10 responden atau 83,3\% dan pelaksanaan TAK kurang baik sebanyak 2 responden atau 16,7\%, sedangkan dari 21 responden yang berpengetahuan kurang baik dan pelaksanaan TAK baik sebanyak 2 responden atau 9,5\% dan yang pelaksanaan TAK kurang baik sebanyak 19 responden atau $90,5 \%$.

Hasil uji Chi-Square diperoleh nilai $\mathrm{p}=0,000$, berarti ada hubungan pengetahuan perawat dengan

Tabel 3

Hubungan Antara Pengalaman Perawat Mengikuti Pelatihan Dengan Pelaksanaan

Terapi Aktivitas Kelompok (TAK) di Ruangan Perawatan Jiwa RSD Madani Propinsi Sulawesi Tengah

\begin{tabular}{|c|c|c|c|c|c|c|c|c|}
\hline \multirow{3}{*}{$\begin{array}{l}\text { Pengalaman } \\
\text { Perawat }\end{array}$} & \multicolumn{4}{|c|}{ Pelaksanaan TAK } & \multirow{2}{*}{\multicolumn{2}{|c|}{ Total }} & \multirow{3}{*}{$\begin{array}{l}\text { p Value; Uji } \\
\text { Chi-square }\end{array}$} & \multirow{3}{*}{$\begin{array}{c}\text { Odds Ratio } \\
\text { (CI 95\%) }\end{array}$} \\
\hline & \multicolumn{2}{|c|}{ Baik } & \multicolumn{2}{|c|}{$\begin{array}{c}\text { Kurang } \\
\text { Baik }\end{array}$} & & & & \\
\hline & $\mathbf{f}$ & $\%$ & $\mathbf{f}$ & $\%$ & $\mathbf{n}$ & $\%$ & & \\
\hline Pernah & 5 & 83,3 & 1 & 16,7 & 6 & 100 & & \\
\hline Tidak Pernah & 7 & 25,9 & 20 & 74,1 & 27 & 100 & 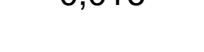 & הט \\
\hline Total & 12 & 36,4 & 21 & 63,6 & 33 & 100 & & \\
\hline
\end{tabular}

Sumber: Data primer 2015

Tabel 3 menunjukkan bahwa dari 33 responden, 6 responden yang pernah mengikuti Pelatihan dan pelaksanaan TAK baik sebanyak 5 responden atau 83,3\% dan pelaksanaan TAK kurang baik sebanyak 1 responden atau $16,7 \%$, sedangkan dari 27 responden yang tidak pernah mengikuti Pelatihan dan pelaksanaan TAK baik sebanyak 7 responden atau $25,9 \%$ dan yang pelaksanaan TAK kurang baik sebanyak 20 responden atau $74,1 \%$.

Hasil dari uji Chi-Square diperoleh nilai $p=0,016$, berarti ada hubungan pengalaman perawat mengikuti pelatihan dengan pelaksanaan Terapi Aktivitas pelaksanaan Terapi Aktivitas Kelompok (TAK) di ruangan perawatan jiwa RSD Madani Propinsi Sulawesi Tengah.

Berdasarkan perhitungan nilai odd ratio, dapat diketahui bahwa perawat yang memiliki pengetahuan kurang baik, berpeluang 47 kali untuk melaksanakan Terapi Aktivitas Kelompok (TAK) dengan kurang baik. dibandingkan dengan perawat yang pengetahuan baik.

\section{b. Hubungan pengalaman perawat mengikuti pelatihan dengan pelaksanaan TAK}


Tabel 4

Hubungan Antara Sikap Perawat Dengan Pelaksanaan Terapi Aktivitas Kelompok

(TAK) di Ruangan Perawatan Jiwa RSD Madani

Propinsi Sulawesi Tengah

\begin{tabular}{|c|c|c|c|c|c|c|c|c|}
\hline \multirow{3}{*}{$\begin{array}{l}\text { Sikap } \\
\text { Perawat }\end{array}$} & \multicolumn{4}{|c|}{ Pelaksanaan TAK } & & & \multirow{3}{*}{$\begin{array}{l}\text { p Value; } \\
\text { Uji Chi- } \\
\text { square }\end{array}$} & \multirow{3}{*}{$\begin{array}{c}\text { Odds } \\
\text { Ratio } \\
\text { (Cl 95\%) }\end{array}$} \\
\hline & \multicolumn{2}{|c|}{ Baik } & \multicolumn{2}{|c|}{ Kurang Baik } & \multicolumn{2}{|c|}{ Total } & & \\
\hline & $\mathbf{f}$ & $\%$ & $\mathbf{f}$ & $\%$ & $\mathbf{f}$ & $\%$ & & \\
\hline Baik & 10 & 71,4 & 4 & 28,6 & 14 & 100 & & \\
\hline Kurang Baik & 2 & 10,5 & 17 & 89,5 & 19 & 100 & & \\
\hline Total & 12 & 36,4 & 21 & 63,6 & 33 & 100 & & \\
\hline
\end{tabular}

Sumber: Data primer 2015

Tabel 4 menunjukkan bahwa dari 33 responden, 14 responden yang bersikap baik dan pelaksanaan TAK baik sebanyak 10 responden atau 74,4\%. Dibanding pelaksanaan TAK kurang baik sebanyak 4 responden atau 28,6\%, sedangkan dari 19 responden yang bersikap tidak baik dan pelaksanaan TAK baik sebanyak 2 responden atau 10,5\%. Dibanding yang pelaksanaan TAK kurang baik sebanyak 17 responden atau $89,5 \%$.

Hasil dari uji Chi-Square diperoleh nilai $p=0,000$, karena nilai $p \leq$ 0,05 , berarti ada hubungan sikap perawat dengan pelaksanaan Terapi Aktivitas Kelompok (TAK) di ruangan perawatan jiwa RSD Madani Propinsi Sulawesi Tengah.

Berdasarkan perhitungan nilai odd ratio, dapat diketahui bahwa perawat yang memiliki sikap kurang baik, berpeluang 21 kali untuk melaksanakan Terapi Aktivitas Kelompok (TAK) dengan kurang baik. Jika dibanding dengan perawat yang sikapnya baik.

\section{PEMBAHASAN}

\section{Hubungan pengetahuan perawat dengan pelaksanaan TAK}

Hasil penelitian pada tabel 2 . diperoleh nilai $p=0,000$, berarti ada hubungan pengetahuan perawat dengan pelaksanaan Terapi Aktivitas Kelompok
(TAK) di ruangan perawatan jiwa RSD Madani Propinsi Sulawesi Tengah.

Berdasarkan perhitungan nilai odd ratio, dapat diketahui bahwa perawat yang memiliki pengetahuan kurang baik, berpeluang 47 kali untuk melaksanakan Terapi Aktivitas Kelompok (TAK) dengan kurang baik. dibandingkan dengan perawat yang pengetahuan baik.

Asumsi peneliti, bahwa ada hubungan antara pengetahuan dengan pelaksanaan TAK disebabkan karena pengetahuan merupakan faktor predisposisi (mempermudah) terjadinya suatu perilaku pada umumnya, dan khususnya pelaksanaan TAK. Pengetahuan merupakan landasan berfikir dalam melaksanakan suatu tindakan. Pengetahuan akan mengarahkan seseorang untuk melakukan suatu tindakan secara benar. Sebaliknya pengetahuan yang kurang baik tentang Pelaksanaan TAK akan membuat perawat kesulitan melaksanakan TAK dengan baik kepada pasien jiwa. Perawat harus mengetahui jenis TAK yang tepat untuk diaplikasikan kepada pasien sesuai dengan masalah yang dialami oleh setiap pasien jiwa. Perawat harus mengetahui dan menetapkan tujuan dari terapi, serta mempersiapkan alat-alat yang dibutuhkan dalam terapi sesuai jenis terapinya. Semua hal tersebut menuntut 
pengetahuan yang baik dari perawat profesional.

Hasil penelitian ini sejalan dengan penelitian Asep (2007), yang bertujuan mencari hubungan antara pengetahuan perawat tentang TAKS dengan motivasi pelaksanaan TAKS di Ruang Rawat Inap Rumah Sakit Jiwa Propinsi Lampung. Penelitian tersebut melibatkan 32 sampel, dengan hasil ada hubungan antara pengetahuan tentang TAKS dengan motivasi perawat untuk melaksanakan TAK.

Hasil penelitian ini didukung pula oleh pendapat Notoatmodjo (2008), bahwa pengetahuan yang baik tentang suatu perilaku kesehatan akan membuat perilaku tersebut bertahan lama (long lasting). Pengetahuan atau kemampuan kognitif individu merupakan domain yang sangat penting dalam membentuk tindakan seseorang. Dari penelitian terbukti bahwa perilaku yang di dasari oleh pengetahuan akan langgeng dari pada perilaku yang tidak didasari oleh pengetahuan.

Menurut Keliat (2007), perawat yang memimpin terapi aktivitas kelompok (TAK), persyaratannya harus mempunyai pengetahuan tentang masalah kesehatan klien dan mengetahui metode yang dipakai untuk kelompok khusus serta terampil berperan sebagai pemimpin.

Menurut Purwaningsih dan Karlina (2009), peran perawat profesional dalam melaksanakan terapi aktivitas kelompok, menuntut pengetahuan yang baik dari perawat. Sebelum melaksanakan terapi aktivitas kelompok, perawat harus terlebih dahulu membuat proposal. Proposal tersebut dijadikan pandual dalam pelaksanaan terapi aktivitas kelompok. Komponen yang dapat disusun meliputi: deskripsi, karakteristik klien, masalah keperawatan, tujuan dan landasan teori, persiapan alat, jumlah perawat, waktu pelaksanaan, kondisi ruangan serta uraian tugas terapis.

\section{Hubungan pengalaman perawat mengikuti pelatihan dengan pelaksanaan TAK}

Hasil penelitian pada tabel 3, diperoleh nilai $p=0,016$, berarti ada hubungan pengalaman perawat mengikuti pelatihan dengan pelaksanaan Terapi Aktivitas Kelompok (TAK) di ruangan perawatan jiwa RSD Madani Propinsi Sulawesi Tengah.

Berdasarkan perhitungan nilai odd ratio, dapat diketahui bahwa perawat yang memiliki tidak memiliki pengalaman mengikuti pelatihan TAK, berpeluang 14 kali untuk melaksanakan Terapi Aktivitas Kelompok (TAK) kurang baik. Dibanding dengan perawat yang memiliki pengalaman mengikuti pelatihan TAK.

Asumsi peneliti, bahwa ada hubungan antara pengalaman mengikuti pelatihan TAK dengan pelaksanaan TAK disebabkan karena pelatihan merupakan bagian penting guna meningkatkan pengetahuan seseorang, khususnya tentang Terapi Aktivitas Kelompok (TAK). Melalui pelatihan, perawat dapat mengingat teori yang sebelumnya pernah didapatkan saat menjalani pendidikan keperawatan. Selain itu, pelatihan merupakan sarana untuk memperoleh pengetahuan yang terbaru mengenai pelaksanaan TAK.

Hasil penelitian ini sejalan dengan hasil penelitian Susilowati (2009) yang berjudul "pengaruh Terapi Aktivitas Kelompok Sosialisasi (TAKS) terhadap tingkat depresi di Rumah Sakit Jiwa Daerah Surakarta," bahwa terdapat pengaruh pemberian perlakuan TAKS terhadap tingkat depresi di Rumah Sakit Jiwa Surakarta. Melalui perhitungan statistika diperoleh nilai t hitung 3,065 dengan nilai $p-v 0,005$.

Hasil penelitian ini didukung pula oleh pendapat Crow dalam Nursalam (2009), bahwa pelatihan adalah suatu proses dimana pengalaman atau informasi diperoleh sebagai hasil dari proses belajar. Makin banyak individu berkesempatan untuk memperoleh pelatihan, maka akan berdampak 
langsung terhadap berbagai tindakan yang dilakukannya.

Menurut Pusdiknakes (2001) dalam Priharjo (2008), bahwa pelatihan dan pendidikan tenaga keperawatan di Indonesia secara umum bertujuan untuk menyediakan tenaga kesehatan dalam jumlah dan jenis yang sesuai, yang memiliki ciri-ciri berbudi luhur, tangguh, cerdas, tarampil, mandiri sesuai dengan asaz profesionalisme masing-masing.

Menurut Potter dan Perry (2005), pengalaman dapat timbul dari pelatihan yang pernah diikuti oleh perawat. Melalui pelatihan, maka individu akan menemukan banyak hal baru untuk meningkatkan pengetahuan dan keterampilannya. Pengalaman adalah cara penting untuk belajar. Pengalaman dalam keperawatan merupakan komponen dari berfikir kritis. Ketika perawat harus menghadapi klien, informasi tentang kesehatan dapat diketahui dari mengamati, merasakan, berbicara dengan klien, dan merefleksikan secara aktif pada pengalaman. Pengalaman klinis memberikan suatu sarana laboratorium untuk menguji pengetahuan keperawatan.

\section{Hubungan sikap perawat dengan pelaksanaan TAK}

Hasil penelitian pada tabel 4, diperoleh nilai $p=0,000$, karena nilai $p \leq$ 0,05 , berarti ada hubungan sikap perawat dengan pelaksanaan Terapi Aktivitas Kelompok (TAK) di ruangan perawatan jiwa RSD Madani Propinsi Sulawesi Tengah.

Berdasarkan perhitungan nilai odd ratio, dapat diketahui bahwa perawat yang memiliki sikap kurang baik, berpeluang 21 kali untuk melaksanakan Terapi Aktivitas Kelompok (TAK) dengan kurang baik. Jika dibanding dengan perawat yang sikapnya baik.

baik.

Asumsi peneliti, bahwa ada hubungan antara sikap dengan pelaksanaan TAK disebabkan karena sikap bersama-sama dengan pengetahuan merupakan faktor predisposisi terjadinya suatu perilaku pada umumnya, dan khususnya pelaksanaan TAK. Sikap merupakan bentuk perilaku yang tertutup (covert behavior) dan merupakan kesiapan untuk bertindak melakukan sesuatu. Sehingga sikap yang kurang baik terhadap pelaksanaan TAK akan membuat perawat melaksanakan TAK dengan kurang baik pula kepada pasien jiwa.

Hal ini didukung oleh pendapat Purwanto (1999), bahwa sikap adalah pandangan atau perasaan yang disertai kecenderungan untuk bertindak sesuai dengan sikap objek tadi.

Menurut Widayatun (1999), sikap adalah keadaan mental dan saraf dari kesiapan, yang diatur melalui pengalaman yang memberikan pengaruh dinamik atau terarah terhadap respons individu pada semua objek dan situasi yang berkaitan dengannya.

Sedangkan menurut Notoatmodjo (2008), sikap merupakan kesiapan atau kesediaan untuk bertindak, dan bukan merupakan pelaksanaan motif tertentu. Sikap belum merupakan suatu tindakan atau aktivitas, akan tetapi merupakan predisposisi tindakan suatu perilaku. Sikap itu masih merupakan reaksi tertutup, bukan merupakan reaksi terbuka, sikap merupakan kesiapan untuk bereaksi terhadap objek di lingkungan tertentu sebagai suatu penghayatan terhadap objek.

\section{KESIMPULAN}

1. Ada hubungan pengetahuan perawat dengan pelaksanaan Terapi Aktivitas Kelompok (TAK) di ruangan perawatan jiwa RSD Madani Propinsi Sulawesi Tengah.

2. Ada hubungan pengalaman perawat mengikuti pelatihan dengan pelaksanaan Terapi Aktivitas Kelompok (TAK) di ruangan perawatan jiwa RSD Madani Propinsi Sulawesi Tengah.

3. Ada hubungan sikap perawat dengan pelaksanaan Terapi Aktivitas 


\section{Kelompok (TAK) di ruangan perawatan jiwa RSD Madani Propinsi Sulawesi Tengah. \\ SARAN}

1. Bagi Perawat, agar mengaplikasikan terapi akifitas kelompok (TAK) dalam pelaksanaan asuhan keperawatan di ruangan perawatan jiwa secara rutin dan bersikap lebih baik,

2. Bagi RSD Madani Propinsi Sulawesi Tengah, agar lebih meningkatkan pelayanan rumah sakit terhadap pasien gangguan jiwa melalui Terapi Aktivitas Kelompok (TAK). Serta meningkatkan pengetahuan perawat melalui pelatihan dan seminar tentang TAK.

\section{DAFTAR PUSTAKA}

Achiryani, 2005, Asuhan Keperawatan Jiwa I, Depkes RI, Jakarta.

Asep,

m/2007/11/hubungan-

pengetahuan-perawat-

dengan.html. Diakses tanggal 1 Oktober 2012.

Dahlan, S, 2006, Statistika untuk Kedokteran dan Kesehatan seri 1; Uji Hipotesis, PT. Arkans, Jakarta.

Erlinafsiah, 2010, Modal Perawat Dalam Praktik Keperawatan Jiwa, TIM, Jakarta.

Keliat, 2007, Buku Saku Keperawatan Medikal Bedah, EGC, Jakarta

Keliat, BA, 2007, Keperawatan Jiwa, EGC, Jakarta.

Machfoedz, I, 2009, Metode Penelitian Bidang Kesehatan, Keperawatan, Kebidanan, Kedokteran, Fitra Maya, Yogyakarta.

Notoatmodjo S, 2007, IImu Perilaku dan Promosi Kesehatan, PT. Rineka Cipta, Jakarta.

, 2008, Promosi Kesehatan: Teori dan Aplikasi, Rineka Cipta, Jakarta.
Nursalam, 2008, Pendekatan Praktis Metodologi Riset Keperawatan, CV Sagung Seto, Jakarta. 2009,

Manajemen Keperawatan Aplikasi dalam Praktik Keperawatan Profesional edisi 2, Salemba Medika, Jakarta.

Sihotang, dkk, Pedoman Penyusunan Proposal/Skripsi, (tidak dipublikasikan).

Potter dan Perry, 2005, Fundemantal Keperawatan, EGC, Jakarta.

Prihajo, R, 2008, Konsep dan Prespektif Praktik Keperawatan Profesional edisi 2, EGC, Jakarta.

Purwaningsih dan Karlina, 2009, Asuhan Keperawatan Jiwa, Nuha Medika Press, Yogyakarta.

RSD Madani Propinsi Sulawesi Tengah. 2015. Laporan Jumlah Pasien Skizofrenia 2012-2015. (Tidak dipublikasikan).

Saryono, 2008, Metodologi Penelitian Kesehatan, Mitra Cendikia, Yogyakarta.

Setiadi, 2008, Riset Keperawatan, Sagung Seto, Jakarta.

Sugiyono, 2011, Statistika Untuk Penelitian, Alfabeta, Bandung.

Sunaryo, 2005, Psikologi untuk Keperawatan, EGC, Jakarta.

Susilowati, 2009, Pengaruh Terapi Aktivitas Kelompok Sosialisasi (TAKS) terhadap tingkat depresi di Rumah Sakit Jiwa Daerah Surakarta,

http://etd.eprints.ums.ac.id/6429, diakses tanggal 5 November 2012.

Tanjung, B, 2005, Pedoman Penulisan Karya IImiah (Proposal, skripsi, dan tesis), Kencana, Jakarta.

Wasis, 2008, Pedoman Riset Praktis untuk Profesi Perawat, EGC, Jakarta.

Yosep, Iyus. 2009. Keperawatan Jiwa. Rafika Aditama: Jakarta. 